\title{
Cooperação Militar no Mercosul e Solução Pacífica de Conflitos Internacionais: Contribuições e Articulações Sub-Regionals
}

\author{
Lairton Ribeiro de Oliveira(*)
}

\begin{abstract}
Resumo: A solução pacífica dos conflitos e a integração regional são temas em evidência no âmbito do Direito e das complexas relações internacionais. Esses temas, aliados a perspectivas para o fortalecimento do multilateralismo, constituem-se no pano de fundo para o desenvolvimento deste trabalho, especificamente em relação ao Mercosul, onde vige um cenário de confiança mútua e cooperação militar, sobretudo no que diz respeito à contribuição com as Nações Unidas para administração e solução de crises e conflitos. Esse ambiente materializa-se, atualmente, na participação conjunta na Missão das Nações Unidas para Estabilização do Haiti — MINUSTAH, considerada como marco inaugural de um novo paradigma de intervenção das Nações Unidas. A partir das hipóteses de alcance de um considerável nível de cooperação militar no Mercosul, bem como de um acúmulo de experiências por participações comuns nas Operações de Paz da ONU, vislumbra-se, como perspectiva, que estão postas as condições para o aprofundamento da integração militar na região, no sentido de se constituir mecanismos conjuntos de treinamento de militares e civis para as referidas operações, bem como para a possível formação de uma Força de Paz Mercosulina para atuar, sob mandato das Nações Unidas, nos conflitos considerados de menor intensidade.
\end{abstract}

Palavras-chave: Mercosul, Cooperação Militar, Solução de Conflitos, Perspectivas de Integração Militar no Mercosul.

\begin{abstract}
The peaceful solution and the regional integration are themes in evidence in Law sphere and in the international complex relations. These themes summed to the strengthening of the Multilateralism, constitute the background for the development of this work, specifically concerning the Mercosur where it exists a scenery of mutual trust and military cooperation rules. This environment currently is materialized in the joint participation of the United Nations Mission for the Stabilization of Haiti - MINUSTAH, which is considered as an inaugural mark of a new intervention paradigm of the United Nations. From the hypothesis of a considerable level of military cooperation in the Mercosur, as well as an accumulation of experiences through common participations, the perspectives are to deepening the military integration in the region, constituting joint mechanisms of military and civilian training to the referred operations, as well as for the possible creation of a Mercosur Peace Force to act, under the mandate of the United Nations, in conflicts considered of low intensity.

Keywords: Mercosur, Military Cooperation, Conflict Solution, Perspectives of Military Integration in Mercosur.
\end{abstract}

(*) Bacharel em Direito e Mestre em Integração Latino-Americana pela Universidade Federal de Santa Maria. E-mail: lairtonsma@gmail.com. Recebido em 24.1.09 e aceito em 27.4.09. 


\section{INTRODUÇÃO}

A dinamicidade e a complexidade das relações entre Estados exigem mecanismos políticos e jurídicos suficientemente compatíveis para orientar a convivência pacífica no sistema internacional. Além disso, a proliferação de atores públicos e privados, cuja influência manifesta-se nas mais diversas situações do cotidiano mundial, requer ampla coordenação, constituindo-se significativo desafio às Relações e ao Direito Internacional ${ }^{(1)}$.

Nesse amplo emaranhado de interconexões, marcado pela defesa de interesses múltiplos e díspares, bem como pelo aprofundamento da desigualdade entre ricos e pobres, interna e externamente aos Estados, não raro surgem divergências que por vezes exacerbam a capacidade de solução, através de meios pacíficos, político-diplomáticos e/ou jurídicos.

Dessas decorrem conflitos em diferentes graus de intensidade que, por seus potenciais danos materiais e humanos, necessitam de tempestiva e firme atuação multilateral internacional, através dos organismos internacionais, para auxiliar, mediar ou impor uma solução, com vistas a minorar o sofrimento das vítimas dos conflitos deflagrados internamente ou entre Estados.

Diante da não consolidação de um Sistema de Segurança Coletivo eficaz, no seio do organismo internacional de alcance universal, as Nações Unidas, e da proliferação de crises e conflitos, sobretudo no interior de Países Menos Avançados (PMA) ${ }^{(2)}$, urge a necessidade de articulação entre Estados para fornecer os meios materiais e humanos àquele organismo, a fim de que possa exercer sua principal competência, a manutenção da paz e da segurança internacionais.

Nesse contexto, esse artigo objetiva o estudo sobre uma problemática acerca da cooperação militar no processo de integração sub-regional do sul da América do Sul, o Mercado Comum do Sul (Mercosul) ${ }^{(3)}$, voltada à atuação conjunta para apoio aos processos de paz conduzidos pela Organização das Nações Unidas (ONU), através de suas Operações de Apoio à $\mathrm{Paz}^{(4)}$.

(1) Cumpre apresentar a definição de Direito Internacional Público, elaborada por Accioly, apud Seitenfus (2006, p. 29): "conjunto de princípios ou regras destinados a reger os direitos e deveres internacionais, tanto dos Estados ou outros organismos análogos, quanto dos indivíduos".

(2) A lista dos 50 Países Menos Avançados, elaborada segundo critérios adotados pelo Conselho Econômico e Social das Nações Unidas (ECOSOC) — Índice de Desenvolvimento Humano (IDH); Boa governança e independência econômica — consta no endereço eletrônico <http://www.un.org/special-rep/ohrlls/ldc/list.htm>. Destes, 34 países pertencem ao continente africano e apenas 1 se encontra na América, o Haiti. Destaque-se que o Cabo Verde está em processo de saída da lista dos PMA, haja vista ter obtido decisão favorável do ECOSOC, no início de 2008, no sentido de promovê-lo ao patamar de País de Desenvolvimento Médio, reduzindo-se, assim, o número de PMA para 49.

(3) A delimitação espacial desse estudo se dá considerando-se os quatro sócios signatários do Tratado de Assunção — que constituiu o Mercosul — (Argentina, Brasil, Paraguai e Uruguai) e o Chile, associado, por este possuir política de apoio às intervenções onusianas, similar aos sócios, constituindo-se a região comumente designada por Cone Sul. Os demais associados e a Venezuela — em processo de adesão como membro pleno —, por não possuírem um significativo histórico de aproximação militar e de contribuição com as Operações de Apoio à Paz, não serão objeto dessa análise, podendo, por óbvio, participar de qualquer mecanismo que venha a ser criado no âmbito do Bloco, no contexto do presente estudo.

(4) Os complexos e multidisciplinares mecanismos de resolução de conflitos recebem atualmente essa denominação. Até então, as intervenções onusianas eram genericamente denominadas de Operações de Paz, as quais compreendiam tanto as Operações de Manutenção da Paz e Operações de Imposição da Paz, baseadas no Cap. VI e VII da Carta de São Francisco, respectivamente. 
Norteado pela problemática traduzida no questionamento sobre o alcance ou não de um patamar mínimo de confiança mútua entre os países do Bloco, capaz de justificar o aprofundamento dos níveis de integração militar, através da formação de Instituições regionais destinadas a servir às Nações Unidas na solução das crises e conflitos, sobretudo recorrentes nos PMA, pretende-se desenvolver o tema sob três eixos.

O primeiro deles destina-se à tentativa de diagnosticar a evolução das ações de demonstração de confiança mútua entre as estruturas político-governamentais e militares, caracterizadora da cooperação militar no âmbito sub-regional (item 1).

Posteriormente (item 2), tentar-se-á evidenciar a contribuição prestada pelos países do Bloco nas atividades desenvolvidas pelas Nações Unidas para a manutenção da paz e da segurança internacionais, cujo ponto culminante reside na atual atuação sul-americana no processo de estabilização do Haiti.

A partir desses eixos temáticos, a terceira parte do trabalho (item 3) destina-se à tentativa de delinear possíveis articulações e perspectivas para consolidação da integração militar no âmbito do Bloco, levando-se em conta a experiência regional nos processos de intervenção onusianos e a necessidade de assunção de maiores responsabilidades pelos países considerados, no contexto de um novo paradigma de solução dos conflitos internacionais, sobretudo em relação à cooperação altruística e solidária com aqueles que ainda se encontram em crise, figurantes da condição de menos avançados.

Convém alertar que o estudo não aborda formas de articulação militar destinadas às tradicionais ações de defesa e segurança, tais como a Organização do Tratado do Atlântico Norte (OTAN), bem como não busca especular sobre a possível criação de um exército do Mercosul, voltando-se apenas a perquirir sobre mecanismos ou arranjos regionais destinados às ações de apoio aos processos de paz.

Portanto, o enfoque principal considera as intervenções realizadas no contexto dos países menos avançados, excluindo-se dos propósitos dessa investigação/proposta as intervenções onusianas de caráter impositivo, realizadas em conflitos entre Estados do Norte - cujos potenciais bélicos superam as possibilidades militares e econômicas dos países Mercosulinos - normalmente realizadas com apoio das potências econômicas e militares setentrionais, tal como foi a "Guerra do Golfo", no início da década de 1990 e a intervenção no Afeganistão, logo no alvorecer deste século.

\section{CoOperação militar no Mercosul}

Analisar aspectos relativos à cooperação militar sub-regional requer uma abordagem geral sobre o contexto normativo internacional a que estão sujeitos os partícipes desta iniciativa.

Para tanto, cumpre referenciar, embora de forma não exaustiva, os principais organismos internacionais de alcance regional e /ou universal, dos quais fazem parte os países do Bloco. 
Inicialmente, destaque-se que tanto os Estados sócios quanto os associados do Mercosul são membros originários da Organização das Nações Unidas(5) e, nessa condição, signatários da Carta de São Francisco que disciplina, mundialmente, a atividade militar externa dos Estados, vedando o recurso à Guerra e às ações unilaterais, excetuados os casos de defesa legítima a uma agressão externa.

A Carta, além de positivar formas de solução pacífica dos conflitos, prevê um Sistema de Segurança Coletivo e define os parâmetros para o emprego do recurso à força, bem como avoca a responsabilidade principal de autorizar, constituir e conduzir os processos de intervenção militar, quando estes se tornam inevitáveis, prescrevendo a obrigação de seus membros em contribuir com os meios necessários.

Inobstante, o capítulo VIII da Carta prescreve a possibilidade de formação de acordos ou entidades regionais a quem podem ser transferidas responsabilidades pela condução de processos de solução de conflitos, com emprego de Força Militar, no âmbito espacial considerado, sob a autorização e supervisão do Conselho de Segurança e de acordo com os ditames onusianos.

Arraigadas em tal permissividade surgem as Organizações regionais, tais como a OEA, em 1948 ${ }^{(6)}$, que segue os preceitos da Carta da ONU, prevendo, em consonância com esta, formas pacíficas de resolução dos conflitos, bem como competências e responsabilidades a serem cumpridas pelos seus membros, em relação aos assuntos correlatos ao emprego militar, sobretudo através de um sistema de segurança coletivo para manutenção da paz e resposta a atos de agressão aos signatários do continente.

A partir desse instrumento regulatório derivam instrumentos normativos, resoluções e foros regionais pan-americanos destinados a coordenar as formas de emprego dos meios militares e as políticas de defesa dos Estados membros.

Importante instrumento a ser considerado é o Tratado Interamericano de Assistência Recíproca (TIAR) ${ }^{(7)}$, correspondente continental às articulações Europeias e Orientais de cunho militar em âmbito regional. O TIAR, apesar de anteceder à OEA, mantém afinidade com esta, pois o principal objeto do Tratado - a assistência recíproca — encontra-se positivado no Cap. VI de sua Carta, ao dispor sobre o mecanismo de Segurança Coletivo continental.

O mecanismo prevê o compromisso dos Estados Americanos de apoiar um Estado que sofra agressão externa, a partir do entendimento de que a agressão a um Estado

(5) Tanto os países sócios do Mercosul — Argentina, Brasil, Paraguai, Uruguai e Venezuela (em processo de admissão como membro) - quanto os associados - Bolívia, Chile, Colômbia, Equador e Peru — fazem parte do grupo de 51 países-membros originários das Nações Unidas, por terem participado da elaboração da Carta e formalizado essa condição, assinando-a e ratificando-a no ano de 1945, conforme estabelece seu art. $3^{\circ}$.

(6) O texto atualizado da Carta da OEA pode ser encontrado em Seitenfus (2004, p.115). Em 1994 a OEA realizou a Reunião de Especialistas sobre Medidas de Fomento da Confiança e Mecanismos de Segurança na Região, cujo documento final estabeleceu importantes medidas na área militar a serem observadas por seus membros, tais como: determinações sobre informação e coordenação de exercícios a serem executados nas áreas de fronteira, intercâmbio de informações orçamentárias, compras, produção, pesquisa, estratégia, organização das forças, intercâmbios de alunos de escolas de formação e aperfeiçoamento de militares, visitas entre unidades militares, compartilhamento de experiências sobre operações de paz e recomendação sobre a necessidade de realização de exercícios conjuntos.

(7) Idem, p. 351. 
deve ser considerada como ofensa a todos os demais ${ }^{(8)}$, cuja ação coletiva se ampara no exercício de um direito imanente de legítima defesa individual ou coletiva, capitulado no art. 51 da Carta das Nações Unidas.

Além do TIAR, devem ser considerados outros mecanismos hemisféricos de coordenação diplomático-militar surgidos antes mesmo da Carta das Nações Unidas, nomeadamente a partir das exigências de coordenação das ações de defesa e segurança do continente no contexto da $2^{\underline{a}}$ Guerra Mundial.

Dentre estes pode ser citada a Junta Interamericana de Defesa (JID) ${ }^{(9)}$, foro internacional criado em 1942, voltado à análise e proposição de medidas necessárias à consolidação da defesa do hemisfério, a partir de estudos elaborados por técnicos militares dos Estados integrantes.

No tocante ao âmbito técnico militar, relativamente a mecanismos regionais de concertação, pode ser citada a Conferência dos Exércitos Americanos (CEA) ${ }^{(10)}$, criada em 1960, a exemplo da Conferência Naval Interamericana e do Sistema de Cooperação das Forças Aéreas, instrumentos idealizados com objetivo de tratar regionalmente os assuntos correlatos a suas missões específicas em relação à segurança.

A CEA, fórum militar multilateral, tenciona aprofundar a integração e a cooperação entre os exércitos dos países do continente americano, bem como elaborar estratégias de defesa contra todas as ameaças à paz, à democracia e à liberdade dos países-membros.

No contexto sub-regional do extremo sul do continente americano, onde se desenvolve um processo de integração sub-regional, originalmente de cunho econômico, ainda não se tem institucionalizadas estruturas militares comuns, apesar de todos os sócios e associados integrarem os organismos supracitados.

Todavia, não se pode negar que diversas iniciativas de aproximação na área militar têm sido aprofundadas bi e multilateralmente, como forma de demonstrar o elevado grau de confiança recíproca, bem como o desenvolvimento da cooperação entre instituições militares, sobretudo em relação à temática da manutenção da paz, administração de crises e conflitos e do compartilhamento de doutrinas e estratégias na área de defesa e segurança.

A partir dessa constatação pretende-se verificar as diversas iniciativas que são adotadas na esfera político-governamental através dos acordos celebrados pelos dirigentes estatais e os mecanismos por eles criados no entorno do tema, e que se traduzem em

(8) O Tratado, assinado em 1947 e em vigor desde 1948, sofreu duro golpe em 1982, por ocasião da Guerra das Malvinas, entre Argentina e Inglaterra. Como os ingleses são parceiros tradicionais dos EUA e ambos integram a Organização do Tratado do Atlântico Norte - OTAN, os EUA ignoraram a previsão do TIAR e cooperaram com a Inglaterra na imposição de uma indigesta derrota aos argentinos, desqualificando o tratado. Esse acontecimento fortaleceu a tese de que o grande objetivo do Tratado foi manter os países americanos aliados aos norte-americanos durante o período da Guerra Fria, contra uma possível investida soviética.

(9) A JID foi criada pela Resolução XXXIX, na Terceira Reunião de Ministros de Relações Exteriores das Repúblicas Americanas, de 22 de janeiro de 1942, no Rio de Janeiro, Brasil. Histórico e demais informações no sítio institucional da JID, $<$ http://www.jid.org/index.php?lang=PT>.

(10) Histórico e informações sobre as atividades da CEA podem ser verificados na página institucional da mesma, no endereço <http://www.redcea.org/HistoricalBackground. aspx? Language=3>. 
ações práticas nas estruturas militares, preliminarmente nos níveis de compartilhamento de conhecimentos, técnicas e doutrinas até o emprego conjunto de tropas militares em exercícios conjuntos.

\section{PrinCIPAIS INICIATIVAS REgIONAIS NA ESFERA POLÍtICO-GOVERNAMENTAL DE REPERCUSSÃO MILITAR}

O espaço geográfico que abriga o mais significativo processo de integração regional da América do Sul, o Mercosul, foi palco, no século XIX, de prolongados e sangrentos conflitos fronteiriços envolvendo, em duas ocasiões, os atuais sócios deste Bloco. Trata-se da Guerra da Cisplatina (1825-1829) — entre Argentina e Brasil — na disputa pelo atual território da República Oriental do Uruguai, na qual o grande vitorioso fora este último, pois obteve o reconhecimento de sua independência ao final do conflito - e, de 1864 a 1870, da Guerra da Tríplice Aliança — Argentina, Brasil e Uruguai — em que os aliados impuseram uma avassaladora derrota ao Paraguai, cujas consequências socioeconômicas até hoje são sentidas.

Apesar disso, o século XX trouxe consigo outra realidade para os povos do Cone Sul do Subcontinente Americano. A realidade belicosa passou a ser substituída gradativamente por aproximações político-diplomáticas e, na área militar, pela substituição de relações guerreiras por iniciativas de convivência pacífica, cooperação e fortalecimento da confiança mútua.

$\mathrm{O}$ quadro a seguir demonstra os principais acontecimentos que sintetizam a evolução:

\begin{tabular}{|l|l|l|l|}
\hline Ano & \multicolumn{1}{|c|}{ Evento } & \multicolumn{1}{|c|}{ Finalidade/CARACTERísticas } & \multicolumn{1}{|c|}{ PARTICIPANTES } \\
\hline 1915 & Pacto ABC & Não agressão, consulta e arbitragem & $\begin{array}{l}\text { Argentina, Brasil e } \\
\text { Chile }\end{array}$ \\
\hline 1932 & $\begin{array}{l}\text { Tratado de } \\
\text { Amizade e } \\
\text { Cooperação }\end{array}$ & $\begin{array}{l}\text { Coordenação de patrulhamento ma- } \\
\text { rítimo }\end{array}$ & $\begin{array}{l}\text { Argentina, Brasil, Pa- } \\
\text { raguai e Uruguai }\end{array}$ \\
\hline 1967 & $\begin{array}{l}\text { Tratado de } \\
\text { Tlatelolco }\end{array}$ & Proscrição de armas nucleares & $\begin{array}{l}\text { América Latina e Ca- } \\
\text { ribe }\end{array}$ \\
\hline $\begin{array}{l}\text { Operação } \\
\text { Condor }\end{array}$ & $\begin{array}{l}\text { Missão policial de informação/coo- } \\
\text { peração na repressão às insurgências } \\
\text { nos regimes militares }\end{array}$ & $\begin{array}{l}\text { Argentina, Bolívia, } \\
\text { Brasil, Chile, Para- } \\
\text { guai e Uruguai }\end{array}$ \\
\hline
\end{tabular}

(11) A década anterior foi marcada pela assunção do poder político pelos militares na América Latina, em especial nos países do Cone Sul, cujas estratégias de defesa consideravam sérias "hipóteses de conflito" entre ambos, fator que não impediu o surgimento, no início da década de 70, de uma polêmica aliança político-militar não ostensiva entre os regimes militares que governavam o Brasil, a Argentina, o Chile, a Bolívia, o Paraguai e o Uruguai, conhecida por "Operação Condor", considerada um acordo com o intento de facilitar a cooperação regional na repressão aos opositores dos regimes detentores do poder, a qual perdurou até a redemocratização destes países, em meados da década seguinte. Sobre este tema, imprescindível é a análise do artigo "Os voos do Condor", Jornal da USP, 13 a 19 de junho de 2005, sobre palestra do jornalista 


\begin{tabular}{|c|c|c|c|}
\hline ANO & EVENTO & FINALIDADE/CARACTERÍSTICAS & PARTICIPANTES \\
\hline 1982 & $\begin{array}{l}\text { Guerra das } \\
\text { Malvinas }\end{array}$ & $\begin{array}{l}\text { Discreto apoio logístico brasileiro à } \\
\text { primeira }\end{array}$ & Argentina e Inglaterra \\
\hline 1985 & $\begin{array}{l}\text { Declaração do } \\
\text { Iguaçu }\end{array}$ & $\begin{array}{l}\text { Ideia de integração econômica e políti- } \\
\text { ca no Cone Sul, } 1 \text { a medida de reorien- } \\
\text { tação da política externa dos países, } \\
\text { emergidos de regimes militares }\end{array}$ & Argentina e Brasil \\
\hline 1986 & $\begin{array}{l}\text { Zona de Paz e } \\
\text { Cooperação }\end{array}$ & $\begin{array}{l}\text { Ampliar o espaço para a integração } \\
\text { e cooperação regional no Atlântico- } \\
\text { Sul, aproximação militar, econômica } \\
\text { e cultural }\end{array}$ & $\begin{array}{l}\text { Leste da América La- } \\
\text { tina e oeste da África }\end{array}$ \\
\hline 1986 & Ata de amizade & Democracia, Paz e Desenvolvimento & Argentina e Brasil \\
\hline 1986 & Grupo do Rio & $\begin{array}{l}\text { Democracia, coordenação, soluções } \\
\text { para crises políticas, repressão a ilíci- } \\
\text { tos, cooperação }\end{array}$ & $\begin{array}{l}\text { América Latina e Ca- } \\
\text { ribe }\end{array}$ \\
\hline 1991 & $\begin{array}{l}\text { Tratado de } \\
\text { Assunção }\end{array}$ & $\begin{array}{l}\text { Instituiu o Mercado Comum do Sul } \\
\text { (MERCOSUL) }\end{array}$ & $\begin{array}{l}\text { Argentina, Brasil, Pa- } \\
\text { raguai e Uruguai }\end{array}$ \\
\hline 1991 & $\begin{array}{l}\text { Acordo de } \\
\text { Cooperação } \\
\text { Nuclear }\end{array}$ & $\begin{array}{l}\text { Desnuclearização militar na região, } \\
\text { emprego para fins pacíficos (energé- } \\
\text { ticos) }\end{array}$ & Argentina e Brasil \\
\hline 1991 & $\begin{array}{l}\text { Compromisso de } \\
\text { Mendoza }\end{array}$ & $\begin{array}{l}\text { Declaração Conjunta para Total Proi- } \\
\text { bição de Armas Químicas e Biológi- } \\
\text { cas }\end{array}$ & $\begin{array}{l}\text { Argentina, Brasil, Chi- } \\
\text { le, Paraguai, Uruguai, } \\
\text { Bolívia e Equador }\end{array}$ \\
\hline 1995 & $\begin{array}{l}\text { Cooperação Militar } \\
\text { Brasileira no } \\
\text { Paraguai }\end{array}$ & $\begin{array}{l}\text { Cooperação permanente, apoio à ins- } \\
\text { trução, compartilhamento de doutrina }\end{array}$ & Brasil e Paraguai \\
\hline $\begin{array}{l}1996 \\
1997 \\
1998\end{array}$ & $\begin{array}{l}\text { Publicação da } \\
\text { Política de Defesa } \\
\text { Nacional }\end{array}$ & Recomendação da OEA em 1995 & $\begin{array}{l}\text { Brasil, Argentina e } \\
\text { Chile respectiva- } \\
\text { mente }\end{array}$ \\
\hline 1997 & $\begin{array}{l}\text { Mecanismo de } \\
\text { Itaipava }\end{array}$ & Consulta e Coordenação Permanente & Argentina e Brasil \\
\hline 1999 & $\begin{array}{l}\text { Declaração de } \\
\text { Zona de Paz } \\
\text { Mercosul }\end{array}$ & $\begin{array}{l}\text { Fortalecimento das medidas de con- } \\
\text { fiança mútua e segurança regional }\end{array}$ & $\begin{array}{l}\text { Sócios do Mercosul, } \\
\text { Bolívia e Chile }\end{array}$ \\
\hline 2005 & $\begin{array}{l}\text { Acordo Quadro } \\
\text { de Cooperação e } \\
\text { Defesa }\end{array}$ & $\begin{array}{l}\text { Fortalecer a cooperação política em } \\
\text { matéria de defesa }\end{array}$ & Argentina e Brasil \\
\hline
\end{tabular}

norte-americano John Dinges, autor da obra "Os anos do Condor", considerada o "mais exaustivo estudo sobre a repressão a militantes de esquerda no Cone Sul nos anos 70, liderada pelo Chile". Ver também Passarinho (2008, p. 13), para quem a Operação Condor “era uma missão de informação, à semelhança da atividade da Interpol”. 


\begin{tabular}{|l|l|l|l|}
\hline Ano & \multicolumn{1}{|c|}{ Evento } & \multicolumn{1}{|c|}{ Finalidade/CARACTERísticas } & \multicolumn{1}{c|}{ Participantes } \\
\hline 2007 & $\begin{array}{l}\text { Memorando de } \\
\text { Entendimento }\end{array}$ & $\begin{array}{l}\text { Participação de tropa paraguaia no } \\
\text { Batalhão Brasileiro de Força de Paz, } \\
\text { atuando no Haiti }\end{array}$ & Brasil e Paraguai \\
\hline 2007 & $\begin{array}{l}\text { Sistema Multilateral } \\
\text { de Operações de } \\
\text { Ajuda em Caso de } \\
\text { Desastres }\end{array}$ & $\begin{array}{l}\text { Organismo criado pelo Comitê de } \\
\text { Comandantes do Exército de Países } \\
\text { do Mercosul }\end{array}$ & $\begin{array}{l}\text { Sócios e Associados } \\
\text { do Mercosul }\end{array}$ \\
\hline
\end{tabular}

Fonte: quadro elaborado pelo autor a partir de, entre outros, documentos publicados nos sítios dos Ministérios de Relações Exteriores dos países considerados.

Os exemplos relacionados, constantes de iniciativas políticas dos governos dos países da região, revelam sensível evolução no estabelecimento das condições para cooperação entre as estruturas militares de defesa no âmbito sub-regional, possibilitando que, atualmente, sejam desenvolvidas atividades conjuntas, entre suas Forças Armadas (FA), notadamente aquelas voltadas à ação externa para solução pacífica dos conflitos e ações de cunho humanitário.

Cumpre-nos, por oportuno, apresentar as principais formas que estão sendo utilizadas para operacionalizar, pelas estruturas militares nacionais, as iniciativas de cooperação definidas regionalmente.

\section{Compartilhamento de doutrina E ESTRATÉgia, EXERCíCios Militares CONJUNTOS E OUTRAS FORMAS DE COOPERAÇ̃̃o (ATIVIDAdES INTEROPERACIONAIS ENTRE as ForÇAS Armadas)}

Delineadas as principais iniciativas políticas expressadas através da atividade soberana estatal de celebrar atos internacionais, em coordenação com outros entes igualmente soberanos, harmonizando seus interesses e buscando o consenso para avançar no processo de integração e cooperação na esfera militar, convém verificar as formas utilizadas para operacionalizar as medidas político-diplomáticas, o que se traduz nas atividades realizadas de forma conjunta pelas Forças Armadas dos países considerados.

Conforme ensina Leira ${ }^{(12)}$, existem três tipos de medidas de confiança desenvolvidas entre os países do Mercosul: a construção da confiança, o seu fortalecimento e a cooperação militar propriamente dita.

A construção da confiança, segundo este autor, acontece a partir de atividades de visitas, de intercâmbio de informações sobre exercícios convencionais e sobre experiências em operações de paz, de participação em seminários, simpósios e conferências bilaterais.

(12) Diego Escuder Leira, em seu artigo "Cooperación Internacional: La Regionalización y las Comunidades de Seguridad. El caso del MERCOSUR", cita a obra de Eduardo Mendizabal "La integración regional militar y la seguridad cooperativa em el âmbito del MERCOSUR ampliado". 
Já as medidas de fortalecimento da confiança circunscrevem-se em ações de intercâmbios de instrutores e alunos nas escolas de formação e especialização, designação de oficiais de ligação entre os países, desenvolvimento de exercícios combinados simulados e no terreno; intercâmbio de informações sobre material de defesa, determinação consensual de princípios de um pensamento estratégico comum, publicação das políticas nacionais de defesa e entendimentos para articular um sistema de cooperação regional.

A cooperação militar propriamente dita se inscreveria, segundo o autor, em atividades de pesquisa e produção de material comum de defesa, determinação de riscos e ameaças comuns, além de estratégias para combatê-los; análise das assimetrias e forma de harmonizá-las, determinações de pautas para relação com outros Estados ou organismos, organização de unidades combinadas para missões de paz e publicação dos orçamentos militares e das aquisições de material.

O quadro exemplificativo a seguir apresenta algumas destas medidas, desenvolvidas no âmbito sub-regional do Mercosul, levadas a efeito pelas tropas das Forças Terrestres:

\begin{tabular}{|c|c|c|c|}
\hline ANO & EVENTO & FinALIDADE & PARTICIPANTES \\
\hline 1991 & $\begin{array}{l}\text { Simpósio sobre es- } \\
\text { tudos estratégicos }\end{array}$ & $\begin{array}{l}\text { Redimensionamento das FA no pro- } \\
\text { cesso de integração }\end{array}$ & Sócios do Mercosul \\
\hline 1993 & $\begin{array}{l}\text { 1 Simpósio dos } \\
\text { Exércitos do Mer- } \\
\text { cosul }\end{array}$ & $\begin{array}{l}\text { Novas funções das FA no processo de } \\
\text { integração }\end{array}$ & $\begin{array}{l}\text { Sócios do Mercosul, } \\
\text { Chile, Bolívia e Peru }\end{array}$ \\
\hline 1995 & $\begin{array}{l}\text { Simpósio sobre Es- } \\
\text { tudos Estratégicos }\end{array}$ & $\begin{array}{l}\text { Os mecanismos de defesa internacio- } \\
\text { nal e os interesses nacionais }\end{array}$ & Países do Cone Sul \\
\hline 1996 & $\begin{array}{l}\text { Operação Cruzeiro } \\
\text { do Sul }\end{array}$ & Operações de Manutenção da Paz & Argentina e Brasil \\
\hline $\begin{array}{l}1997- \\
2000\end{array}$ & $\begin{array}{l}\text { Operação Cruzeiro } \\
\text { do Sul }\end{array}$ & $\begin{array}{l}\text { Treinamento da tropa para Operações } \\
\text { de Manutenção da Paz }\end{array}$ & $\begin{array}{l}\text { Todos os Membros } \\
\text { do Mercosul }\end{array}$ \\
\hline $\begin{array}{l}2000 \\
2001\end{array}$ & $\begin{array}{l}\text { Exercício de Apoio } \\
\text { Humanitário }\end{array}$ & $\begin{array}{l}\text { Apoio humanitário em caso de catás- } \\
\text { trofes naturais }\end{array}$ & Argentina e Brasil \\
\hline $\begin{array}{l}2001 \\
2002\end{array}$ & Operação Cabañas & $\begin{array}{l}\text { Treinamento da tropa para Operações } \\
\text { de Manutenção da Paz }\end{array}$ & $\begin{array}{l}\text { Membros do Merco- } \\
\text { sul e EUA }\end{array}$ \\
\hline $\begin{array}{l}2001- \\
2004\end{array}$ & Exercício Laço Forte & $\begin{array}{l}\text { Exercício de emprego convencional } \\
\text { das FA em conflitos clássicos }\end{array}$ & Argentina e Brasil \\
\hline 2006 & $\begin{array}{l}\text { Operação Herman- } \\
\text { dad }\end{array}$ & $\begin{array}{l}\text { Ações convencionais ofensivas, de- } \\
\text { fensivas e de resistência }\end{array}$ & $\begin{array}{l}\text { Sócios do Mercosul, } \\
\text { Chile e Bolívia }\end{array}$ \\
\hline
\end{tabular}

Fonte: quadro elaborado pelo autor, a partir de informações disponibilizadas nas homepages institucionais, das Forças Armadas dos países considerados, bem como em periódicos publicados pelas mesmas.

Além desses exercícios, de significativa repercussão nacional em cada um dos sócios e associados do Mercosul, outros intercâmbios e reuniões regionais são realizados nas áreas de fronteira por unidades dos Exércitos ali situadas. 
Apesar de os exercícios realizados pelas Forças Terrestres - Exércitos - obterem grande projeção, inclusive com ampla cobertura midiática, as demais Forças, Navais e Aéreas, também realizam exercícios conjuntos em proporções similares, bi e multilateralmente, buscando a ação coordenada para a defesa dos espaços aéreo e marítimo.

Além dos exercícios de treinamento propriamente ditos, há que se mencionar outras atividades, frequentemente desenvolvidas, tais como as visitas, os intercâmbios, os seminários, as reuniões entre os militares da região, realizadas para consolidar a confiança mútua e a condição de um entorno regional pacífico, bem como para propiciar oportunidade de coordenação de possíveis ações integradas em situação real.

Resultante dessas medidas de aproximação, no final de 2007, a título de exemplo, uma Força-Tarefa composta por integrantes das Forças Armadas brasileiras atuou solidariamente em operações de ajuda humanitária em solo boliviano ${ }^{(13)}$, realizando buscas, resgates, transportes de pessoas, distribuição de alimentos e medicamentos ante a situação de calamidade decorrente de enchentes e inundações que assolaram o departamento de Beni, naquele país.

No contexto da integração entre os militares do Mercosul se inserem ainda atividades de cooperação técnica entre as FA do Bloco, voltadas à formação e especialização de pessoal, pesquisa e produção de material de emprego militar ${ }^{(14)}$ e missões de apoio permanente.

Nesse sentido, em fevereiro de 2008 foram anunciadas pela imprensa brasileira tratativas entre Brasil e Argentina para conclusão de acordo na área de defesa, em três perspectivas:

[...] uma parceria entre o governo argentino e a Embraer, segundo o qual a empresa brasileira assumirá o controle de uma fábrica de aviões na província de Córdoba (atualmente em mãos da americana Lockheed); um acordo para dar impulso à produção conjunta do veículo militar "gaúcho" (usado para o transporte de tropas); e um amplo memorando de cooperação em matéria de defesa (FIGUEIREDO e OLIVEIRA, 2008) ${ }^{(15)}$.

A partir do levantamento das progressivas atividades de integração e cooperação militar entre países-membros do Bloco, cabe explorar acerca de outra atividade incidental a todas as demonstradas, qual seja a experiência adquirida pelas FA dos países integrantes do Bloco, individual e coletivamente, ao longo de uma história de participação em Operações de Paz conduzidas pela ONU e pela OEA, geradoras de apreciável expertise no gerenciamento de crises e conflitos internacionais.

(13) Conforme noticiado pelo Jornal Zero Hora eJB Online, em 14.2.08, disponibilizados eletronicamente em: <http://www. exercito.gov.br/Resenha/homepage.htm>.

(14) Exemplo dessa atividade é o Projeto de Intercâmbio Científico-Tecnológico, desenvolvido entre os Exércitos do Brasil e da Argentina para produção de um veículo militar leve de emprego geral aerotransportável, que recebeu o nome de Gaúcho, apresentado em março de 2007 e atualmente já sendo empregado pelo Exército Argentino.

(15) Disponível em: <http://www.exercito.gov.br/Resenha/homepage.htm>. À mesma época houve especulações acerca da possibilidade de construção conjunta de um submarino de propulsão nuclear. 


\section{CONTRIBUiÇão COMUM PARA MANUTENÇÃo DA PAZ}

Paralelamente às ações desenvolvidas no campo político-governamental e entre estruturas militares de defesa dos países que integram o Mercosul, voltadas ao aprofundamento da confiança mútua, estes países em consonância com os princípios e fundamentos das Nações Unidas - da qual são membros originários - participam ativamente dos mecanismos por ela empregados para a solução e administração de crises e conflitos internacionais — as Operações de Apoio à Paz.

Pode-se afirmar que, desde as primeiras iniciativas voltadas à manutenção da paz e da segurança internacionais, patrocinadas pela ONU, os países integrantes do Mercosul foram construindo um histórico de contribuição que hodiernamente se traduz em apreciável banco de informações, experiência e conhecimentos, através dos efetivos que fizeram e fazem parte dos processos de imposição, manutenção, construção e estabelecimento da paz, nas mais variadas regiões do mundo, onde a Organização é chamada ou vê-se no dever de intervir.

O quadro seguinte apresenta uma síntese das principais participações mercosulinas, com os efetivos empregados por cada país, tanto nas Operações de Paz da ONU, quanto em iniciativas pacificadoras adotadas regionalmente fora do contexto daquela organização.

\begin{tabular}{|c|c|c|c|c|c|c|c|}
\hline Missão & LOCAL & Período & ARGENTINA & BRASIL & Paragual & URUGUAI & ChILE \\
\hline $\begin{array}{l}\text { Observadores } \\
\text { Militares }\end{array}$ & $\begin{array}{l}\text { Bolívia- } \\
\text { Paraguai }\end{array}$ & $\begin{array}{l}1929- \\
1936\end{array}$ & (1) & (1) & - & 03 & (1) \\
\hline UNSCOB & Bálcas & $\begin{array}{c}1948- \\
1949\end{array}$ & - & 02 & - & - & - \\
\hline $\begin{array}{l}\text { Observadores } \\
\text { Militares }\end{array}$ & Equador-Peru & $\begin{array}{c}1942- \\
1960\end{array}$ & (1) & - & - & - & - \\
\hline UNMOGIP & $\begin{array}{l}\text { Índia- } \\
\text { Paquistão }\end{array}$ & $1952-\ldots$ & - & - & - & $72-3 *$ & $4^{*}$ \\
\hline UNEF I & $\begin{array}{l}\text { Sinai-Faixa } \\
\text { Gaza }\end{array}$ & $\begin{array}{l}1957- \\
1967\end{array}$ & - & 6.300 & - & - & - \\
\hline UNOGIL & Líbano & 1958 & 04 & - & - & - & (1) \\
\hline ONUC & Congo & $\begin{array}{l}1960- \\
1964\end{array}$ & - & 179 & - & - & - \\
\hline UNSF & $\begin{array}{l}\text { Nova Guiné } \\
\text { Ocidental }\end{array}$ & 1962 & - & 02 & - & - & - \\
\hline UNFICYP & Chipre & $\begin{array}{l}1964- \\
1967\end{array}$ & - & 20 & - & $18^{*}$ & - \\
\hline UNIPOM & $\begin{array}{l}\text { Índia- } \\
\text { Paquistão }\end{array}$ & $\begin{array}{l}1965- \\
1966\end{array}$ & - & 10 & - & - & - \\
\hline FIP & $\begin{array}{l}\text { República } \\
\text { Dominicana }\end{array}$ & $\begin{array}{l}1965- \\
1966\end{array}$ & - & 1.450 & - & - & - \\
\hline
\end{tabular}




\begin{tabular}{|c|c|c|c|c|c|c|c|}
\hline Missão & LOCAL & Período & ARGENTINA & BRASIL & Paragual & URUGUAI & CHILE \\
\hline ONUVT & $\begin{array}{l}\text { Oriente } \\
\text { Médio }\end{array}$ & $\begin{array}{c}1967 \\
-\ldots\end{array}$ & 93 & - & - & - & $02 *$ \\
\hline $\begin{array}{l}\text { Observadores } \\
\text { Militares }\end{array}$ & $\begin{array}{l}\text { El Salvador- } \\
\text { Honduras }\end{array}$ & $\begin{array}{c}1970- \\
1980\end{array}$ & (1) & (1) & - & - & (1) \\
\hline MFO & Sinai & $1981-\ldots$ & - & - & - & $\begin{array}{c}1.853- \\
87^{*}\end{array}$ & - \\
\hline UNIMOG & Irã-Iraque & $\begin{array}{l}1988- \\
1991\end{array}$ & 28 & - & - & 37 & - \\
\hline Golfo Pérsico & $\begin{array}{l}\text { Iraque- } \\
\text { Kuwait }\end{array}$ & $\begin{array}{l}1990- \\
1991\end{array}$ & (1) & - & - & - & - \\
\hline UNAVEM I & Angola & $\begin{array}{l}1988- \\
1991\end{array}$ & & 16 & - & - & - \\
\hline UNAVEM II & Angola & $\begin{array}{l}1991- \\
1995\end{array}$ & 36 & 120 & - & - & - \\
\hline MONUA & Angola & $\begin{array}{l}1997- \\
1999\end{array}$ & & 35 & - & 07 & - \\
\hline ONUCA & $\begin{array}{l}\text { América } \\
\text { Central }\end{array}$ & 1990 & (2) & 34 & - & - & - \\
\hline UNIKOM & $\begin{array}{l}\text { Iraque- } \\
\text { Kuwait }\end{array}$ & $\begin{array}{l}1991- \\
2003\end{array}$ & 1.316 & - & - & 54 & 189 \\
\hline $\begin{array}{l}\text { UNAMIK } \\
\text { APRONUC }\end{array}$ & Camboja & $\begin{array}{l}1991- \\
1993\end{array}$ & 04 & - & - & 1.330 & 104 \\
\hline MINURSO & $\begin{array}{l}\text { Saara } \\
\text { Ocidental }\end{array}$ & $\begin{array}{l}1991- \\
2004\end{array}$ & 22 & (1) & - & 78 & - \\
\hline UNPROFOR & Croácia & $\begin{array}{l}1992- \\
1995\end{array}$ & 6.495 & 90 & - & - & - \\
\hline ONUSAL & $\begin{array}{l}\text { El Salvador- } \\
\text { Honduras }\end{array}$ & 1993 & (2) & 67 & - & - & 23 \\
\hline UNMIH & Haiti & $\begin{array}{l}1993- \\
1996\end{array}$ & (2) & - & - & - & - \\
\hline $\begin{array}{l}\text { Remoção de } \\
\text { Minas }\end{array}$ & Nicarágua & 1993 & (2) & - & - & 03 & 02 \\
\hline UNOMIL & Libéria & 1993 & - & 03 & - & 44 & - \\
\hline ONUMOZ & Moçambique & $\begin{array}{l}1993- \\
1994\end{array}$ & 06 & 284 & - & 2.518 & - \\
\hline UNFICYP & Chipre & $\begin{array}{c}1993 \\
-\ldots\end{array}$ & 7.195 & $02 *$ & - & - & $26^{* * *}$ \\
\hline
\end{tabular}




\begin{tabular}{|c|c|c|c|c|c|c|c|}
\hline Missão & LOCAL & Período & ARGENTINA & BRASIL & Paragual & URUGUAI & ChILE \\
\hline UNOMUR & $\begin{array}{l}\text { Uganda- } \\
\text { Ruanda }\end{array}$ & $\begin{array}{l}1993- \\
1994\end{array}$ & - & 13 & - & - & - \\
\hline MARMINCA & $\begin{array}{l}\text { América } \\
\text { Central }\end{array}$ & $1994-\ldots$ & - & $60^{*}$ & - & - & - \\
\hline UNOMIG & Geórgia & $1994-\ldots$ & - & - & - & $03 *$ & - \\
\hline UNOMIR & Ruanda & $\begin{array}{c}1994- \\
1995\end{array}$ & 01 & - & - & 46 & - \\
\hline MINUGUA & Guatemala & $\begin{array}{l}1994- \\
2000\end{array}$ & 01 & 39 & - & 23 & - \\
\hline UNMOT & Tajiquistão & $\begin{array}{l}1994- \\
2000\end{array}$ & - & - & - & 35 & - \\
\hline UNCRO & Croácia & $\begin{array}{l}1995- \\
1996\end{array}$ & - & 02 & - & - & - \\
\hline UNAVEM III & Angola & $\begin{array}{l}1995- \\
1997\end{array}$ & - & 4.174 & - & 2.506 & - \\
\hline MOMEP & Equador-Peru & $\begin{array}{l}1995- \\
1999\end{array}$ & 62 & 192 & - & - & 114 \\
\hline UNPREDEP & $\begin{array}{l}\text { Ex-Rep. Yug } \\
\text { Macedônia }\end{array}$ & $\begin{array}{l}1995- \\
1997\end{array}$ & 02 & 05 & - & - & - \\
\hline $\begin{array}{l}\text { CASCOS } \\
\text { BLANCOS }\end{array}$ & Angola & $\begin{array}{c}1995- \\
1998\end{array}$ & (3) & - & - & - & - \\
\hline UNTAES & $\begin{array}{l}\text { Eslavônia- } \\
\text { Croácia }\end{array}$ & $\begin{array}{c}1996- \\
1998\end{array}$ & 220 & 11 & - & - & - \\
\hline UNSCOM & Iraque & $\begin{array}{c}1996- \\
1998\end{array}$ & (2) & 03 & - & - & $51 *$ \\
\hline UNMIBH & Bósnia & 1997-... & 20 & - & - & - & $34^{*}$ \\
\hline UNMIBIH & $\begin{array}{l}\text { Bósnia- } \\
\text { Herzegovina }\end{array}$ & $\begin{array}{l}1997- \\
2002\end{array}$ & - & - & - & - & 103 \\
\hline MONUP & $\begin{array}{l}\text { Província } \\
\text { Prevlaka }\end{array}$ & $\begin{array}{l}1996- \\
2002\end{array}$ & 08 & 11 & - & - & - \\
\hline UNAMSIL & Serra Leoa & 1999-... & - & - & - & $11^{*}$ & - \\
\hline UNAMET & Timor Leste & $\begin{array}{l}1999- \\
2000\end{array}$ & - & 07 & - & $05^{*}$ & - \\
\hline INTERFET & Timor Leste & $\begin{array}{l}1999- \\
2000\end{array}$ & - & 51 & - & - & - \\
\hline UNMEE & $\begin{array}{l}\text { Eritreia- } \\
\text { Etiópia }\end{array}$ & $2000-\ldots$ & - & $07^{*}$ & $04^{*}$ & $46^{*}$ & - \\
\hline
\end{tabular}




\begin{tabular}{|c|c|c|c|c|c|c|c|}
\hline Missão & LOCAL & Período & ARGENTINA & Brasil & Paragual & URUGUAI & СHILE \\
\hline MONUC & Congo & $2000-\ldots$ & - & - & $17^{*}$ & 3.560 & $(04)$ \\
\hline UNMOVIK & Iraque & $\begin{array}{l}2000- \\
2003\end{array}$ & - & - & - & - & 1 \\
\hline UNMIK & Kosovo & $2001-\ldots$ & 03 & - & - & - & $1 *$ \\
\hline UNTAET & $\begin{array}{l}\text { Timor } \\
\text { Oriental }\end{array}$ & $\begin{array}{l}2001- \\
2003\end{array}$ & 12 & 349 & - & - & 163 \\
\hline UNMSET & Timor Leste & $\begin{array}{l}2002- \\
2005\end{array}$ & - & 175 & - & - & 06 \\
\hline MINUCl & $\begin{array}{l}\text { Costa do } \\
\text { Marfim }\end{array}$ & $\begin{array}{l}2003- \\
2004\end{array}$ & - & 04 & - & $11^{*}$ & - \\
\hline MARMINAS & Peru-Equador & $2003-\ldots$ & - & $05^{*}$ & - & - & - \\
\hline UNMIL & Libéria & $2003-\ldots$ & - & - & $04^{*}$ & - & - \\
\hline UNAMA & Afeganistão & $2003-\ldots$ & - & - & - & $1^{*}$ & - \\
\hline ONUB & Burundi & $\begin{array}{l}2004- \\
2006\end{array}$ & - & - & 03 & - & - \\
\hline UNOCI & $\begin{array}{l}\text { Costa do } \\
\text { Marfim }\end{array}$ & $2004-\ldots$ & - & $07 *$ & $11 *$ & - & - \\
\hline MIFH & Haiti & 2004 & - & - & - & - & 331 \\
\hline MINUSTAH & Haiti & $2004-\ldots$ & 2.116 & $1.216^{*}$ & $33^{*}$ & $1.142^{*}$ & $589 *$ \\
\hline UNOGIBS & Guiné-Bissau & $2004-\ldots$ & - & $01 *$ & - & - & - \\
\hline UNMIS & Sudão & $2005-\ldots$ & - & $24^{*}$ & $06^{*}$ & - & - \\
\hline UNMIT & Timor Leste & $2000-\ldots$ & - & $04^{*}$ & - & - & - \\
\hline
\end{tabular}

Fonte: quadro elaborado pelo autor, a partir de informações obtidas dos seguintes sítios da Internet: <www.

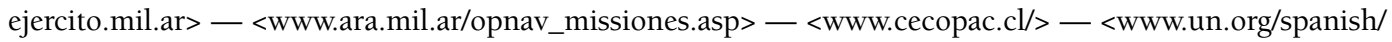

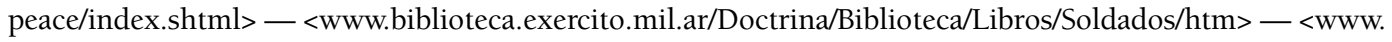
un.int/chile/misionesdepaz> — <www.exercito.gov.br/04Maoami/missaopaz/indice.htm $>-<$ www.batalhaosuez.com.br/ForcasDePazBreveHistorico.htm> — http://www.imae.edu.uy/eope/resena_histrica.html>.

Observações:

${ }^{(*)} \mathrm{O}$ efetivo participante nos contingentes enviados, no sistema de rodízio, semestral ou anualmente.

${ }^{(*)}$ O efetivo paraguaio de 1 pelotão de fuzileiros (32 militares) e 1 Oficial de Estado Maior integra a tropa brasileira desde 2006, quando foi assinado um acordo entre os dois países, o qual viabilizou essa integração.

${ }^{(* *)} \mathrm{O}$ efetivo chileno nessa missão integra o contingente argentino servindo à UNFICYP.

(1) Os países participaram dessa missão através do fornecimento de grupos de observadores.

(2) A Argentina participou dessas missões com quatro equipamentos e tropas especializadas de sua Marinha.

(3) A Argentina criou uma organização, pelo seu executivo, voltada a desenvolver tarefas humanitárias, através das Nações Unidas. Grupos de Cascos Blancos atuaram em diferentes atividades em Angola.

${ }^{(4)} \mathrm{O}$ Chile participou dessa missão através do envio de uma Unidade Aeromédica do Exército. 
A partir desse diagnóstico nota-se que, mesmo se tratando de países em vias de desenvolvimento - atores que ocupam posição intermediária no cenário internacional -, os Estados mercosulinos sustentam um importante papel quando se trata da paz e da segurança mundial, notadamente quando as crises se desenvolvem em países ainda mais deficitários em termos políticos, sociais e econômicos, figurantes no grupo dos menos avançados.

Conforme afirma Battaglino, acerca da participação dos mercosulinos em missões de paz, "o Uruguai é o país da região que mais efetivos tem em missões, situando-se em

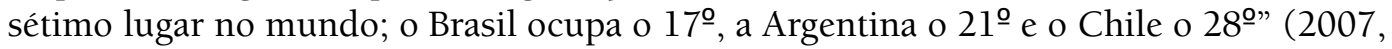
p. 16).

A preocupação em preparar e capacitar seus efetivos diante dos novos e complexos desafios que se apresentam às intervenções da ONU, sobretudo as multidisciplinares, complexas ou de segunda geração, fez com que os sócios e associados do Mercosul, a partir da década de 1990 passassem a criar estruturas nacionais voltadas à qualificação de efetivos, militares e civis, a serem empregados nas atividades de manutenção da paz.

Em 1994, o governo uruguaio criou o Sistema Nacional de Apoio às Operações de Manutenção de Paz (SINOMAPA) e, no ano seguinte, o Centro de Instrução para Operações de Paz do Exército. No ano de 1998, esse Centro transformou-se na Escola de Operações de Paz do Exército $(\mathrm{EOPE})^{(16)}$, denominação mantida até os dias atuais.

A Argentina, por seu turno, criou em 1995 o Centro Argentino de Treinamento Conjunto para Operações de Paz $\left(\right.$ CAECOPAZ) ${ }^{(17)}$, direcionado ao treinamento e especialização do pessoal nacional e internacional, designado a compor os efetivos para Missões de Paz.

O CAECOPAZ tornou-se um centro de referência internacional de preparação de pessoal, catalogação de experiências, produção científica e apoio às Nações Unidas no desenvolvimento de doutrinas e técnicas a serem difundidas aos potenciais peacekeepers. Nesse sentido, a colaboração de Dugone e Isaac:

Daí o surgimento do CAECOPAZ, como centro estratégico e acadêmico. Começamos a elaborar nosso próprio material didático-bibliográfico, a manter os conteúdos atualizados [...] e divulgar o CAECOPAZ por meio de publicações internacionais. [...] Assim produzimos, intercambiamos e interpretamos conceitos doutrinários de operações de paz e aspectos educativos. Nosso objetivo é favorecer um ambiente de trabalho pró-ativo e produtivo que permitirá ao centro antecipar-se às necessidades e desafios da natureza mutante dos conflitos e das operações de paz para adaptar o processo de qualificação à realidade na área da missão. (2006, p. 14)

Seguindo tendência congênere, em 2002, o Chile criou seu Centro Conjunto para Operações de Paz (CECOPAC), com a missão primordial de,

(16) Ver o sítio oficial da Escola, no endereço <http://www.imae.edu.uy/eope/resena_historica.html>.

(17) Sítio institucional no endereço eletrônico: <www.caecopaz.mil.ar/caecopaz.html>. 
Preparar y entrenar al personal militar, policial y civil, nacional y extranjero, para participar en misiones internacionales, conforme a compromisos adoptados en ese sentido con la Organización de Naciones Unidas u otros organismos internacionales, brindar asesoría técnica al Ministro de Defensa Nacional, efectuar estudios, investigaciones en la materia y mantener un registro de los principales acuerdos e iniciativas internacionales en materia de operaciones de paz. ${ }^{(18)}$

O Brasil, apesar de sua expressiva participação em Operações de Paz das Nações Unidas, somente no ano de 2005, motivado pelo numeroso contingente enviado semestralmente ao Haiti para compor a MINUSTAH, criou seu Centro de Instrução de Operações de Paz, cujas missões institucionais são:

Contribuir para a pesquisa, o desenvolvimento e a validação da doutrina de emprego da Força Terrestre no tocante às Op. Paz; planejar e conduzir cursos e estágios, a fim de especializar e adestrar militares, frações, subunidades e unidades para a atuação em Op. Paz; [...] preparar os militares designados para cursos de Op. Paz no exterior; preparar observadores militares e oficiais de Estado-Maior designados para Op. Paz; cooperar com a formação de recursos humanos das demais Forças Armadas, das Forças Auxiliares ou de órgãos governamentais [...] (VERDE OLIVA, 2006, p.12).

O caso brasileiro é emblemático, pois por ter tardiamente tomado a decisão de constituir um centro dessa magnitude, possivelmente tenha deixado de catalogar e consolidar conhecimentos e experiências advindas da diversificada forma de emprego de seus nacionais em Operações de Paz, em distintas regiões do mundo e em diferentes contextos tático-operacionais, elementos essenciais ao desenvolvimento de novas doutrinas e técnicas a serem empregadas na administração e solução de conflitos.

Inobstante, as instituições militares mercosulinas contam com o privilégio de possuir uma considerável experiência na solução pacífica dos conflitos internacionais, construída desde antes do surgimento das Nações Unidas, bem como pode ostentar a condição de possuidora de importantes centros de memória, pesquisa, desenvolvimento de doutrinas e técnicas, preparação e qualificação de efetivos destinados a servirem às Nações Unidas.

Nesse sentido foi criada, em dezembro de 2007, na cidade de Buenos Aires, a Associação Latino-Americana de Centro de Treinamentos para Operações de Paz (ALCOPAZ), com o objetivo de ser uma entidade de âmbito regional:

[...] conformada por centros gobernamentales de países latinoamericanos y del Caribe, dedicadas fundamentalmente al entrenamiento de miembros de las Fuerzas Armadas, Fuerzas de Seguridad y personal civil destinados a intervenir en operaciones de paz bajo mandato de las Naciones Unidas. $(2007)^{(19)}$

(18) Histórico do Centro, disponível no endereço eletrônico: <http://www.cecopac.cl>.

(19) Conforme informação noticiada pelo Ministério de Defesa da Argentina, a reunião de criação da associação contou com a presença de "representantes militares de Uruguay, (SINOMAPA, Sistema Nacional de Apoyo a las Operaciones de Mantenimiento de la Paz); Chile (CECOPAC, Centro Conjunto para Operaciones de Paz); Brasil (CIOP, Centro de Instrucción de Operaciones de Paz); Peru (CECOPAZ, Centro de Entrenamiento Conjunto de Operaciones de Paz); Guatemala 
Essa iniciativa multilateral pode ser entendida como representativa do resultado parcial de um longo processo de aproximação entre as estruturas governamentais e de defesa da região, além do alinhamento das Políticas Externas latino-americanas que se voltam, ativamente, a um tema atualmente tão complexo e caro à humanidade, qual seja o esforço para manutenção da paz entre os povos e a mitigação do sofrimento humano através da solução pacífica das crises e conflitos internos e internacionais.

Dessa forma, a partir do rol de iniciativas aqui diagnosticadas, é possível afirmar que se multiplicam as demonstrações de confiança mútua, principalmente no âmbito sub-regional e que propiciam, na atualidade, a conquista de relativo sucesso ${ }^{(20)}$ na condução conjunta - por tropas militares e funcionários governamentais civis desses países - do processo de pacificação da sociedade haitiana, através da Missão das Nações Unidas para Estabilização do Haiti — MINUSTAH ${ }^{(21)}$.

É forçoso constatar que a grande maioria do pessoal integrante da estrutura de comando da missão, tanto na esfera civil como militar, constitui-se de latino-americanos.

Conforme Manaut, "pela primeira vez uma missão da ONU foi encabeçada por diplomatas latino-americanos. O chefe da missão é [à época] do Chile (embaixador Juan Gabriel Valdés) e a chefia da missão militar coube a generais brasileiros"(22) $(2006$, p. 32).

De igual sorte, Tápia afirma:

A atual operação de paz no Haiti é a primeira dessa natureza na região latino-americana da qual não participa nenhuma potência. Também é a primeira que é assumida em matéria

(CREMOPAZ, Comando Regional de Entrenamiento de Operaciones de Mantenimiento de la Paz); Ecuador (UEMPE); y la Argentina (CAECOPAZ, Centro Argentino de Entrenamiento Conjunto para Operaciones de Paz)". Disponível em: <http:// www.mindef.gov.ar/info.asp?Id=1347>.

(20) Cabe destacar que se trata de percepção contemporânea, com base em resultados tabulados passados quatro anos do início da intervenção. No entanto, ressalte-se que, principalmente em sua fase inicial, a intervenção no Haiti sofreu várias críticas, por diversos aspectos, dentre eles: o suposto golpe de Estado contra o Presidente, legitimamente eleito, Jean Bertrand Aristid, em fevereiro de 2004, precedente à intervenção; interligado a este, a opinião contrária da Comunidade do Caribe (CARICOM), a qual não reconheceu o governo provisório, por ser precedido de ação antidemocrática golpista e, mesmo assim, não foi considerada; o suposto interesse direto dos países envolvidos, como França e Canadá, que visariam uma reaproximação aos EUA, após forte oposição aos EUA na invasão ao Iraque, bem como dos principais contribuintes com tropas - Chile, Argentina e Brasil — também críticos dos EUA no episódio citado e que buscavam a reaproximação, além da visibilidade internacional através do emprego de suas Forças Armadas, fator positivo para suas pretensões futuras, distintamente do ideal altruístico e humanitário apresentado oficialmente; e, também, a forte atuação dos próprios militares, no combate aos rebeldes, por vezes denunciada por organismos de defesa dos Direitos Humanos. Sobre uma abordagem crítica da intervenção, ver TOKATLIÁN (2005).

(21) Esta é a quinta missão onusiana no Haiti. Conforme informações obtidas na página http://www.un.org/spanish/peace/ dpko/index.asp, das Nações Unidas, as atividades deste organismo no Haiti se deram através das seguintes missões: UNMIH (Missão das Nações Unidas no Haiti, 1993-1996, cujo mandato previa a assistência à modernização das Forças Armadas do Haiti e estabelecimento de uma nova força policial. Sua fase inicial fracassou ante a falta de cooperação pelas forças militares locais; após o retorno do governo constitucional, em 1994, o mandato converteu-se para a preparação das eleições ocorridas em 1996); UNSMIH (Missão de Apoio das Nações Unidas no Haiti, 1996-1997, cujo mandato previa a assistência ao governo na profissionalização da polícia nacional e apoio ao desenvolvimento institucional, reconciliação nacional e reabilitação econômica); UNTMIH (Missão de Transição das Nações Unidas no Haiti, 1997, com mandato novamente voltado ao apoio à profissionalização da polícia); MIPONUH (Missão de Polícia das Nações Unidas no Haiti, 1997-2000, voltada à assistência, supervisão e formação de unidades especializadas da polícia local).

(22) Atualmente o Representante Especial do Secretário-Geral — SGSR, chefe da missão, é o Diplomata M. Hédi Annabi, da Tunísia, que assumiu a função em outubro de 2007, substituindo o guatemalteco Edmond Mullet, chefe da missão entre maio de 2006 e outubro de 2007. O chileno Juan Gabriel Valdés esteve à frente da MINUSTAH de junho de 2004 a maio de 2006. 
militar, principalmente com esforços dos países da região. Desse ponto de vista, é um marco de responsabilidade e maturidade regional em matéria de segurança, por certo, respeitando a legalidade internacional (2005, p. 58).

Essencialmente na Força Militar, a grande maioria do pessoal empregado advém da América do Sul, contexto em que se destacam os numerosos contingentes dos países integrantes do Mercosul, conforme o quadro a seguir:

\begin{tabular}{|l|c|l|l|}
\hline PAÍ́ CONTRIBUINTE & EFETIVOS & & \multicolumn{1}{|c}{ ESPECIALIDADES } \\
\hline ARGENTINA & 550 & Infantaria, Aviação, Hospital Militar \\
\hline BOLÍVIA & 205 & Infantaria \\
\hline BRASIL & 1.267 & Infantaria, Engenharia \\
\hline CHILE & 557 & Infantaria, Engenharia, Aviação \\
\hline EQUADOR & 66 & Engenharia \\
\hline GUATEMALA & 113 & Polícia Militar \\
\hline JORDÂNIA & 718 & Infantaria \\
\hline NEPAL & 1.066 & Infantaria \\
\hline PERU & 204 & Infantaria \\
\hline FILIPINAS & 154 & Infantaria \\
\hline SRI LANKA & 949 & Infantaria \\
\hline URUGUAI & 1.122 & Infantaria \\
\hline PARAGUAI & 31 & Infantaria \\
\hline DIVERSOS & 103 & Militares nacionais desses países, com funções de Estado \\
\hline Total & 7.105 & Diversas \\
\hline
\end{tabular}

Fonte: quadro elaborado pelo autor com informações obtidas no endereço <http://minustah.org/?page $\mathrm{id}=10727 \&$ postTabs $=1>$.

O quadro demonstra a amplitude da participação latino-americana, em especial dos países do Cone Sul, na estrutura militar da MINUSTAH. Considerando-se a contribuição dos cinco países dessa região - Argentina, Brasil, Uruguai, Paraguai e Chile —, aproxima-se aos expressivos 50\% do total dos efetivos militares da missão.

De igual sorte, multiplicando-se o efetivo aproximado de 3.000 militares mercosulinos, pelo número de contingentes, substituídos em média a cada seis meses, (até agora já transcorreram dez semestres desde o início da missão), chega-se ao expressivo número que ultrapassa 30.000 militares $^{(23)}$, os quais já estiveram atuando conjuntamente, sob a bandeira das Nações Unidas, como peacekeepers no país caribenho.

(23) Não estão considerados os militares que permaneceram por mais de seis meses e os que participaram por mais de uma ocasião, em diferentes contingentes, o que reduziria a estimativa em termos absolutos. 
A essas estatísticas convergem depoimentos em reconhecimento aos países da região, agentes desse contexto, que podem ser considerados, pelo menos, como uma mudança de perfil das intervenções onusianas para a mediação e solução de conflitos.

Dentre essas observações, destaca-se a seguinte leitura:

Pela primeira vez na história da ONU, um grupo de Estados que desempenham um papel secundário no sistema internacional respondem a um apelo do CS compondo a missão de estabilização no Haiti (MINUSTAH). A inédita composição do grupo de Estados mediadores coloca a indagação sobre o fato de nos encontrarmos no limiar de uma nova etapa da mediação e da solução de conflitos, através de um instrumento coletivo e desinteressado. Ou seja, um grupo de países que não possuem interesses políticos, ideológicos, econômicos ou militares. Além disso, inexistem grandes interesses internacionais (SEITENFUS, 2006, p. 15) [grifos nossos].

Valendo-se das estatísticas sobre a participação militar mercosulina nas atividades de apoio à paz, especialmente na constituição do Componente Militar da MINUSTAH, torna-se possível avançar no desenvolvimento deste trabalho, com o objetivo de traçar perspectivas acerca das possíveis formas de aproveitamento da experiência em atuação conjunta, adquirida pelos militares da região, nos diversos contingentes que já fizeram dos mecanismos de solução de conflitos das Nações Unidas.

\section{ArticulaÇões E PERSPECTIVAS}

A principal perspectiva, vislumbrada a partir das constatações supra, diz respeito à possibilidade de constituição de um mecanismo regional destinado a participar de intervenções multilaterais — por organismos internacionais para elas legitimados — consentidas e humanitárias.

Primordialmente, descarta-se de plano a modalidade intervenção unilateral, considerando-se esta como desconstrução do Direito Internacional, ante ao entendimento de que a legalidade de uma intervenção militar reside na prévia existência de um mandato expedido pelas Nações Unidas ${ }^{(24)}$.

O objetivo de limitar a atuação de uma possível estrutura regional destinada a operações de paz criadas para intervenções consentidas e humanitárias se inscreve no contexto da capacidade das Forças Armadas dos países da região.

Acredita-se que um organismo de tal natureza não estaria militar e politicamente apto a promover uma intervenção em conflitos tradicionais entre Estados, situação que exige um desdobramento amplo de recursos financeiros e equipamentos militares, os quais as estruturas militares desses países ainda se ressentem.

(24) O Conselho de Segurança detém a competência para impor sanções e usar a força, no contexto do capítulo VII da Carta. No entanto, para compor situações ocorridas em períodos de latência do Conselho, a AG reservou para si uma competência subsidiária para criar Operações de Paz, nos casos em que o CS não consegue decidir devido a divergências entre os Membros Permanentes, o que impede a ação do Conselho diante da regra da unanimidade, traduzida no "poder de veto". Nesse sentido, a AGNU aprovou a Resolução n. 377, adotada em 3 de novembro de 1950, "União para Manutenção da Paz", a qual prevê a possibilidade de a AG recomendar aos Membros, "inclusive, caso tratar-se de uma ruptura da paz ou de um ato de agressão, a utilização de força armada em caso de necessidade, para manter ou restabelecer a paz e a segurança internacionais". O texto da Resolução encontra-se em Seitenfus (2004, p. 140). 
Acrescente-se que a delimitação proposta impediria a participação desse possível mecanismo nas coalizões defensivas ou ofensivas, de forma a priorizar a atuação em questões internas, conflitos de menor intensidade e na solução de crises humanitárias, típicas de Estados menos avançados, as quais, em alguns casos, também necessitam de capacidade para ações impositivas, porém em menor amplitude, tal como ocorre atualmente no Haiti.

Alguns internacionalistas, atentos à possibilidade de aprofundamento das relações militares na região e levando em consideração o nível atual de cooperação e entendimento, admitem essa perspectiva.

Nesse sentido, Covarrubias, ao abordar sobre "as missões das Forças Armadas na atualidade", quando se manifesta sobre a presença latino-americana no Haiti expressa:

Um ponto particularmente relevante, já que está servindo de base para uma organização militar combinada mais adiante, são as medidas de confiança mútua. A partir do Haiti, efetuou-se um acordo argentino-chileno para que suas forças atuem combinadamente em operações de paz. Também se organizou uma companhia de engenheiros chileno-equatorianos e um batalhão brasileiro integrado por oficiais da Bolívia e do Paraguai, todos passos muito relevantes de integração militar. De todo modo, é preciso enfatizar que a integração militar não é complicada: difícil é a integração política, e esta é a base de tudo.

[...] a transformação das Forças Armadas na região tendente à organização de alguma estrutura militar combinada deve começar com a transformação da concepção política de seu emprego (2007, p. 80-82).

O desenvolvimento de mecanismos regionais ou estruturas militares combinadas, voltadas à atuação na mediação e solução de conflitos, encontra amparo na Carta das Nações Unidas, porquanto expresso em seu Capítulo VIII:

ARTIGO 52 - 1. Nada na presente Carta impede a existência de acordos ou de entidades regionais, destinadas a tratar dos assuntos relativos à manutenção da paz e da segurança internacionais que forem suscetíveis de uma ação regional, desde que tais acordos ou entidades regionais e suas atividades sejam compatíveis com os Propósitos e Princípios das Nações Unidas. [...]

ARTIGO 53 - 1. O Conselho de Segurança utilizará, quando for o caso, tais acordos e entidades regionais para uma ação coercitiva sob a sua própria autoridade.[...] (CARTA da ONU, 1945)

Ante a dinâmica dos conflitos atuais, percebe-se que a maioria deles se desenvolve no âmbito interno dos Estados, em situações complexas de desagregação social e institucional que, por sua amplitude, podem constituir uma ameaça à paz e à segurança internacional, possibilitando a intervenção multilateral.

É forçoso admitir que, para os casos de conflitos de menor intensidade, não basta um amplo aparato bélico dotado de militares altamente treinados para conflitos armados tradicionais, mas sim de tropas leve ou medianamente armadas, treinadas para atuar em 
ambiente urbano, em missões que ora são tipicamente militares de uso da força, ora são missões de cunho político-social, de assistência humanitária e até mesmo de reconstrução de infraestrutura e de reestruturação institucional.

Diante do presente cenário há que se admitir, também, que as potências militares e econômicas mundiais normalmente não estão dispostas a investir seus recursos em treinamento e capacitação dessa natureza, a partir do entendimento de que suas tropas devem ser preparadas para situações de conflitos de maior potencial, nos moldes tradicionais, de forma a manter a capacidade dissuasória em relação a potenciais inimigos, pelo treinamento e aprimoramento da capacidade defensiva e ofensiva da força militar.

Reconhece-se, pois, que a ONU tem sua atuação restringida pela insuficiência de pessoal militar e civil preparados para enfrentar os conflitos que se proliferaram após o término da Guerra Fria, sobretudo os que se desenvolvem nos limites territoriais dos Estados, cujo saldo de vítimas supera as estatísticas dos maiores conflitos bélicos já vistos.

Nota-se a necessidade da criação de mecanismos para preparar e organizar forças de reserva das Nações Unidas, para emprego emergencial, cuja responsabilidade cabe aos Estados-Membros, o que podem fazer articuladamente no âmbito regional.

Verifica-se, ademais, o surgimento de um espaço de atuação a ser ocupado articuladamente por Estados que buscam fortalecer seu prestígio internacional, embora não possuindo as características clássicas para tanto - poderio militar e desenvolvimento econômico - , mas que, por outro lado, possuem capacidade para desempenhar um papel ativo nas questões de paz e segurança, através da contribuição com as Nações Unidas nas suas Operações de Apoio à Paz.

Conforme o diagnóstico elaborado na seção precedente, pode-se afirmar que os sócios do Mercosul parecem já ter alcançado um patamar mínimo de entendimento que, somado à relativa experiência adquirida por seus militares em atividades de solução pacífica dos conflitos internacionais - situação demonstrada atualmente na atuação conjunta no processo de estabilização do Haiti — , permite avançar nesse processo, através da criação de uma estrutura regional de preparação de efetivos para as operações de paz, bem como de uma Força Conjunta, permanentemente mantida em condições de ser rapidamente desdobrada para atender às solicitações das Nações Unidas e ser empregada no campo do estabelecimento e da manutenção da paz, sobretudo nos conflitos de menor intensidade, preservando-se a compatibilidade dos meios militares necessários a esta modalidade de intervenção, com a potencialidade bélica dos países mercosulinos.

Não é diversa a postura de Tápia, ao constatar que:

[...] Os vizinhos do Cone Sul se encontram em melhores condições de estabilidade, tanto política como econômica, e podem ser sócios ativos e interessados em uma projeção internacional, onde obviamente a preocupação com um entorno de paz e segurança ocupa um lugar destacado. Isso explicaria a coordenação tipo ABC (Argentina, Brasil e Chile) que podemos observar no caso haitiano.

[...] Os três países estão convencidos de que é necessária uma ativa inserção internacional, que é indispensável um mundo regulado conforme o direito e fortalecer o papel das Nações Unidas, e que para isso é indispensável o acordo entre países da região. (2005, p. 49) 
Uma contribuição mais efetiva poderia advir de um mecanismo de concertação ou até mesmo de unificação dos diversos centros de treinamento e preparação existentes na Argentina, Brasil, Chile, Paraguai e Uruguai, bem como da formação de uma Força de Paz mercosulina, semelhante ao modelo europeu ${ }^{(25)}$, que se constitui em Grupos de Batalha de reação rápida para servir em missões da ONU, desdobráveis num prazo de 15 dias com capacidade para permanecer no mínimo 150 dias em missão.

Não se trataria de um mecanismo de defesa e segurança, aos moldes das alianças defensivas tradicionais como a OTAN, nem mesmo um Exército do Mercosul, mas simplesmente uma organização voltada à prevenção de conflitos, resolução de crises e auxílio às operações humanitárias, sob os auspícios das Nações Unidas.

A justificativa para um empreendimento dessa natureza pode ser encontrada na argumentação de Annan, ao se referir ao genocídio de Ruanda, em 1994, pois, segundo ele:

Seguramente, las cosas podrían haber sido distintas si el Consejo de Seguridad hubiera podido disponer de un pequeño pero rápido contingente de reacción, preparado para desplazarse con un plazo de pocos días. Creo que para evitar este tipo de desastre en el futuro necesitamos tener esa capacidad de reacción; los Estados Miembros deben contar con contingentes de reserva bien entrenados, disponibles de forma inmediata, y estar dispuestos a enviarlos tan pronto como el Consejo de Seguridad lo solicite (1999).

A factibilidade de uma estrutura militar regional foi defendida recentemente por Seitenfus, durante a IV Reunião sobre Operações de Paz, organizada pelo Governo Brasileiro. Naquela oportunidade, o doutrinador sugeriu:

[...] que fossem criados centros de treinamento das Operações de Paz do Mercosul, se trataria, portanto, de uma estratégia coletiva. Seria a primeira organização de integração a existir, pois nem a União Europeia tem estrutura semelhante. Com um centro coletivo os custos seriam diminuídos, haveria troca de experiências e um atendimento semelhante ao que temos no Haiti seria criado, mas diferentemente daquele país, aqui seria permanente. Há instalações militares nos países do Mercosul, especificamente no Brasil, que estão sendo subutilizadas. Teríamos a capacidade de abrigar este projeto. Do ponto de vista político-diplomático, um Centro de Treinamento de Operações do Mercosul poderia não ser somente um centro para os soldados dos quatro países-membros, mas também um centro que abrigaria militares de outros países que porventura viessem aqui treinar. Certamente a construção deste centro teria um impacto político-diplomático extraordinário para o país (2005, p. 66).

Não se pode olvidar, no entanto, a proeminente postura do Uruguai, país ocupante da $7^{\underline{a}}$ posição no ranking dos países que mais contribuem com tropas para as Operações de Paz no âmbito das Nações Unidas, pois em 1993, durante o Simpósio sobre "Relaciones de los ejércitos de la región con la Organización de las Naciones Unidas”, por intermédio do seu Exército, sugeriu, dentre outras, a possibilidade da criação de uma "forma de cooperação técnica-profissional a ser encarada a nível regional":

(25) Sobre o assunto, o artigo de Karl Buck, "Defesa e segurança no século XXI", na obra Segurança internacional: políticas públicas e cooperação bi-regional, um diálogo Europa-América do Sul. 2005. p. 26-30. 


\section{Creación de un Sistema Regional de Apoyo a la ONU en Operaciones de Mantenimiento de La Paz:}

Aprovechando la dinámica de las relaciones existentes en los países del área y sus Ejércitos, producto de indisolubles lazos históricos, afianzados en diversos acuerdos de integración en marcha, podría crearse un "Sistema Regional de Apoyo a la ONU en Operaciones de Mantenimiento de la Paz", el que funcionaría al más alto nivel de las Fuerzas de los países del área.

La cooperación institucionalizada que se lograría a nivel de los Ejércitos alcanzaría aspectos de organización, entrenamiento, equipamiento, transporte, envío de tropas, etc., pudiendo facilitar todos los enlaces y coordinaciones necesarias para todas y cada una de las posibles formas de cooperación técnico profesional y cumplir en última instancia y en mejor forma los objetivos de nuestros Gobiernos de proveer medios, convenientemente capacitados y entrenados, para mantener la paz y seguridad internacional, mediante una adecuada participación en Operaciones de Mantenimiento de la Paz, como instrumento válido de evitar conflictos (1993) [sem grifos no original].

Nota-se, portanto, sobretudo após a participação conjunta iniciada em 2004 na estabilização do Haiti(26) ${ }^{(2)}$ que parecem estar postas as condições para a evolução do pensamento político-estratégico regional, no âmbito da participação em operações de paz das Nações Unidas, no sentido de se institucionalizar um mecanismo regional de treinamento e preparação de tropas para servirem como peacekeepers, bem como para a institucionalização de uma Força de Paz comum, que se mantenha constantemente preparada para ser rapidamente empregada nas fases iniciais dos conflitos, deficiência ainda não corrigida pelas Nações Unidas.

A paradigmática missão no país caribenho permite conjecturar a possibilidade de um concerto que possa ir além da composição puramente militar dos meios. A participação de diversos diplomatas e especialistas da área jurídica, eleitoral, infraestrutural e política, dentre outras, designados para ocupar postos-chaves na estrutura de comando da missão, credencia os sul-americanos, e em especial os mercosulinos, a continuarem contribuindo para a paz e a segurança internacionais, a partir do nível de expertise atingido.

Um centro integrado regional de treinamento de pessoal para servir em missões de paz poderia incluir, além dessas atividades, a relevante participação de atores não estatais, como as Organizações da Sociedade Civil, que desempenham funções nas áreas de conflito e têm um papel preponderante, principalmente no contexto da consolidação da paz.

O Mercosul, apesar de ainda não ter atingido plenamente seus objetivos previstos no Tratado constitutivo, apresenta considerável nível de cooperação e aperfeiçoamento em diversas áreas de interesse na resolução de crises e conflitos.

(26) Ousaríamos afirmar aqui que, para a formação de um organismo regional comum, bastaria empregar parte do pessoal civil e militar, que já atuou conjuntamente na MINUSTAH, para mobiliar toda a estrutura necessária à operacionalização dessa nova Instituição regional. Note-se que existe pessoal especializado, haja vista que já ocorreram aproximadamente dez rodízios entre o pessoal participante da missão e, em todos eles, especialistas e autoridades civis e militares mercosulinas ocuparam as mais variadas funções nas estruturas de comando, logística, operacional e outras, de cunho eminentemente civil, da referida missão. 
Além das supramencionadas iniciativas de Cooperação Militar, sobretudo a partir da redemocratização, pode-se afirmar que vicejam, no interior do Bloco, princípios democráticos como a alternância no poder, processos eleitorais transparentes e eficientes, afirmação das instituições estatais, bem como se aprimora o desenvolvimento tecnológico - principalmente na área da produção de energia e de alimentos — e se afirmam projetos de cooperação e iniciativas em atividades de economia solidária.

Tais características não devem ser desconsideradas, ao passo que essas áreas são as que mais necessitam de apoio, após o estabelecimento das condições mínimas de segurança pela força militar, para a reestruturação e o desenvolvimento de uma sociedade arrasada pelos conflitos internos ou externos.

Observa-se, portanto, que os países integrantes do Mercosul, principalmente seus sócios e o Chile, associado, comungam de características similares em suas Políticas Externas, fatores que os credenciam a melhor explorar seus potenciais de colaboração com a paz e a segurança no mundo - através de uma cooperação mais ativa e profunda com a possibilidade de aumentarem, legítima e pacificamente, seus graus de influência e de prestígio perante a Sociedade Internacional, diversamente das potências que o fazem através do poderio militar e econômico.

Inobstante, podem também, altruisticamente, envidar esforços para redução do sofrimento humano naquelas regiões que pouco ou nada têm a oferecer aos "ricos do Norte" e, por isso, passam ao largo de suas agendas.

\section{CONSIDERAÇÕES FINAIS}

Apesar de a produção e divulgação do conhecimento científico — relativo à temática abordada nessa análise - encontrar-se em estágio ainda inicial, a partir dos fatores ora evidenciados, pode-se inferir que, no âmbito do Mercosul, as práticas de demonstração de confiança mútua encontram-se em fase significativamente avançada, o que se verifica desde as atitudes governamentais, representadas pelos acordos e arranjos regionais, até a materialização da cooperação através da realização de exercícios militares conjuntos, bem como a ação interoperacional em situações reais de emprego militar, nos processos de paz das Nações Unidas.

Essas práticas demonstram, ademais, a consolidação do multilateralismo e o respeito ao Direito Internacional como princípios norteadores das relações externas dos Estados-partes do Mercosul, aqui considerados, haja vista que a ação militar externa se dá, essencialmente, sob os ditames das Cartas Constitutivas dos organismos regionais e internacionais.

Verifica-se também uma tendência comum de ação pró-ativa na solução de crises e conflitos, representada pela busca de melhores níveis de preparação e aperfeiçoamento de civis e militares, para atuarem em cenários de crises e conflitos, priorizando-se o apoio à ONU nas questões envolvendo países pobres do Sul, o que denota um viés solidário e humanitário, na execução da política externa dos Estados sob análise.

Nesse sentido, sobretudo a partir das características da participação mercosulina na MINUSTAH, bem como em outras missões de paz nas quais esses países contribuíram, 
verifica-se uma incipiente mudança de paradigma nos processos de intervenção, agora se priorizando a ação multidimensional, liderada por países não potências, levadas a efeito por motivações diversas da estrita defesa dos interesses nacionais diretos e preocupada com uma solução duradoura, não só pela intervenção militar rápida, mas através da elaboração de um projeto de consolidação da paz, embasado na reestruturação socioeconômica, política e institucional dos países anfitriões.

Inobstante, pelo significativo avanço na demonstração da confiança mútua e da implementação de diversas modalidades de cooperação militar no Mercosul, bem como da experiência acumulada pela intensa participação em operações de paz da ONU, nota-se que parecem estar presentes as condições necessárias para o aprofundamento da integração, sobretudo no sentido da conjugação efetiva dos esforços em contribuir com aquele organismo, através da institucionalização de um mecanismo regional permanente de preparação de militares e civis para essas operações, bem como pela formação de uma Força de Paz conjunta, constantemente mantida, para pronto emprego em atenção aos chamados onusianos.

Não se pode olvidar — a partir de uma possível consolidação da integração multilateral militar regional no âmbito do Mercosul, voltada ao alcance de solução pacífica e/ou coercitiva para conflitos considerados de menor intensidade - da possibilidade de interlocução com outros processos de integração regional, como a União Europeia por exemplo, que comunguem dos mesmos princípios de atuação externa sob os auspícios das Nações Unidas.

Medidas dessa natureza viriam ao encontro dos desafios atualmente enfrentados pelo Direito Internacional para garantir o imperativo humanitário, a disciplina das dinâmicas e complexas relações internacionais, a prevalência do multilateralismo na solução pacífica dos litígios e a monopolização dos meios coercitivos pelo organismo multilateral de alcance universal, as Nações Unidas, buscando-se a convivência pacífica, democrática e igualitária pelos integrantes do sistema internacional e a cooperação solidária entre os Estados, comprometida com o ideal cosmopolítico.

\section{REFERÊNCIAS BIBLIOGRÁFICAS}

AMARAL, Gilberto. Solidariedade. JB Online. Brasília. 14 fev. 2008. Disponível em: <http://www. exercito.gov.br/Resenha/homepage.htm> Acesso em: 14 fev. 2008.

ANNAN, Koffi A. El problema de la intervención. Nueva York: Naciones Unidas, 1999.

ARGENTINA. EA. Exército Argentino. Informações e documentos oficiais sobre instituição. Disponível em: <http://www.ejercito.mil.ar/>. Acesso em: 13 jan. 2008.

Ministério de la Defensa. Fundación de la Asociación Latinoamericana de Cientros de Entrenamiento para Operaciones de Paz. Información de Prensa Nr 300/07. 6 dez. 2007. Disponível em: <http://www.mindef.gov.ar/info.asp?Id=1347>. Acesso em: 15 jan. 2007.

BATAGLINO, Jorge. A América do Sul, a União Europeia e a Segurança Internacional... In: HOFMEISTER, Wilhelm (Org.). Segurança internacional. Rio de Janeiro: Konrad-Adenauer-Stiftung, 2007.

BRASIL. Exército Brasileiro. Centro de Instrução de Operações de Paz. Revista Verde Oliva. Ano XXXIII, n. 190. Out./Nov./Dez. 2006. Brasília/DF. 
EB. Exército Brasileiro. Informações e documentos oficiais sobre instituição. Disponível em: <http://www.exercito.gov.br>. Acesso em: 20 jan. 2008.

. MD. Ministério da Defesa. Informações e documentos institucionais sobre o organismo. Disponível em: <http://www.defesa.gov.br>. Acesso em: 19 nov. 2007.

. Ministério das Relações Exteriores. Divisão de Atos Internacionais. Disponível em: <http:// www2.mre.gov.br/dai.htm>. Acesso em: 15 mar. 2008.

BUCK, Karl. Defesa e Segurança no século XXI. In: VALLADÃO, Alfredo... et al. (Orgs.). Segurança internacional. Rio de Janeiro: Konrad-Adenauer-Stiftung, 2005.

CEA. Conferência dos Exércitos Americanos. Informações e documentos institucionais sobre o organismo. Disponível em: <http://www.redcea.org/>. Acesso em: 14 dez. 2007.

CHILE. Ejército de Chile. Informações e documentos oficiais sobre instituição. Disponível em:<http:// www.ejercito.cl/>. Acesso em: 28 mar. 2008.

COVARRUBIAS, Jaime G. A OEA e as questões de segurança e defesa. In: HOFMEISTER, Wilhelm. (Org.). Segurança internacional. Rio de Janeiro: Konrad-Adenauer-Stiftung, 2007.

DUGONE, Alaciel C.; ISAAC, Gustavo G. O centro argentino de adestramento combinado para as operações de paz. Military Review, 2006. p. 11-16.

FIGUEIREDO, J.; OLIVEIRA, E. Brasil e Argentina vão fechar acordo na área de defesa. O Globo. 19 fev. 2008. Disponível em: <http://www.exercito.gov.br/Resenha/homepage.htm>. Acesso em: 19 fev. 2008.

JID. JUNTA DE DEFESA INTERAMERICANA. Informações e documentos institucionais sobre o organismo. Disponível em: <http://www.jid.org>. Acesso em: 14 dez. 2007.

LEIRA, Diego Escuder. Cooperación Internacional: la regionalización y las comunidades. Centro de Estudios Hemisféricos de Defensa. Universidad Nacional de Defensa. EUA. Disponível em: <http:// www.ndu.edu/chds/docUploaded/SRC05URU-PDF/Escuder-URY-SeminarioCHDSMVD-UY-DiegoEscuder.pdf>. Acesso em: 23 nov. 2007.

MANAUT, Raúl B. América Latina: os debates e ações militares internacionais das forças armadas. In: HOFMEISTER, Wilhelm. (Org.). Segurança internacional. Rio de Janeiro: Konrad-AdenauerStiftung, 2006.

MERCOSUL. Tratado de Assunção. Disponível em: <http://www.mercosur.int/msweb/principal/ contenido.asp>. Acesso em: 12 jul. 2007.

MIGUEL, Sylvia. Os voos do Condor revelados. Jornal da USP, São Paulo, ano XX, n. 728, 13-19 jun. 2005. Disponível em: <http://www.usp.br/jorusp/arquivo/2005/jusp728/pag0405.htm>. Acesso em: 7 jul. 2008.

MINUSTAH. Missão das Nações Unidas para estabilização do Haiti. Informações e documentos institucionais sobre o organismo. Disponível em:<http://www.minustah.org/>. Acesso em: 10 dez. 2007.

ONU. DPKO. Cronologia das operações de PazdaONU. Disponível em: <http://www.un.org/spanish/ peace/dpko/cronologia/>. Acesso em: 21 jan. 2008.

. ORGANIZAÇÃO DAS NAÇÕES UNIDAS. Informações e documentos oficiais sobre a organização. Disponível em: <http:// www.un.org/>. Acesso em: 8 jan. 2008.

PASSARINHO, Jarbas. Operação Condor. Revista do Clube Militar: a casa da República. Ano LXXXI, n. 428 , abr. 2008.

SEITENFUS, Ricardo. A manutenção da paz e as lições do Haiti: colapso ou reedificação do Estado? In: OBREAL/EULARO specialist papers. São Paulo, 2006.

. Elementos para uma diplomacia solidária. IV Reunião de Estudos: operações de paz. Brasília: Gabinete de Segurança Institucional; Secretaria de Acompanhamento e Estudos Institucionais, 2005. 
Legislação internacional. Barueri/SP: Manole, 2004.

; VENTURA, Deisy. Direito internacional público. 4. ed. Porto Alegre: Livraria do Advogado, 2006.

TÁPIA, Gabriel G. Haiti. Considerações geopolíticas, balanço e projeções. In: VALLADÃO, Alfredo et al. (Orgs.). Segurança internacional. Rio de Janeiro: Konrad-Adenauer-Stiftung, 2005.

TOKATLIÁN, Juan Gabriel. Intervención en Haití, misión frustrada. Una crítica de América Latina. 2005. Disponível em: <http://www.fride.org/publicacion/102/intervencion-en-haiti-mision-frustrada-una-critica-de-america-latina>. Acesso em: 20 mar. 2008.

URUGUAY. Ejército Nacional. Fuerzas de paz: la experiência del Ejército de Uruguay. Simposio en Buenos Aires. Jun. 1993. Disponível em: <http://www.ser2000.org.ar/articulos-revista-ser/revista-5/ uruguay.htm>. Acesso em: 26 out. 2007.

EOPE. Escola de Operações de Paz do Exército. Informações e documentos oficiais sobre instituição. Disponível em: <http://www.imae.edu.uy/eope/resena_historica.html>. Acesso em: 20 fev. 2008. 